\title{
ANALISIS DAYA TARIK WISATA BAHARI DENGAN PENDEKATAN SUPPLY DAN DEMAND: STUDI DI TELUK KILUAN
}

\author{
Levyda Levyda ${ }^{1}$, Yunice Marisa ${ }^{2}$ \\ Fakultas Ekonomi dan Bisnis, Universitas Sahid, Jakarta \\ Jl. Soepomo No 84, Jakarta Selatan \\ Email Korespondensi:levyda_mm@yahoo.co.id
}

\begin{abstract}
ABSTRAK
Penelitian ini bertujuan untuk mengidentifikasi daya tarik wisata bahari di Taman Wisata Perairan Teluk Kiluan Kabupaten Tanggamus Povinsi Lampung. Penelitian ini menggunakan pendekatan supply dan demand. Pendekatan supply dilakukan dengan menganalisis hasil studi literatur dan observasi tentang sumber daya yang berpotensi menjadi daya tarik, yang mencakup kualitas air laut, kualitas pasir pantai, keragaman ikan dan terumbu karang, pasir pantai, jumlah iklan lumba lumba dan atraksinya, dan fauna. Analsis supply dilakukan berdasarkan hasil studi literatur dan observasi. Sedangkan pendekatan demand dilakukan dengan menganalisis persepsi wisatawan tentang potensi daya tarik wisata. Analisis demand ilakukan berdasarkan hasil survey kepada wisatawan dan pendapat wisatawan tentang daya tarik wisata di media sosial. Berdasarkan analisis supply dan demand disimpulkan bahwa daya tarik Teluk Kiluan adalah lumba-lumba, pasir pantai, dan keragaman ikan dan karang.
\end{abstract}

Kata Kunci: Daya tarik wisata, wisata pantai, wisata bahari, pendekatan supply \& demand, teluk kiluan

\begin{abstract}
This study aims to identify the attractiveness of marine tourism in Taman Teluk Air Teluk Kiluan Tanggamus Lampung. This study uses a supply and demand approach. This study uses a supply and demand approach. The supply approach is carried out by analyzing the results of literature studies and observations of potentially fascinating resources, including seawater quality, sand beach quality, diversity of fish and coral reefs, coastal sand, dolphin advertising and attractions of dolphins, and fauna. While the demand approach is carried out by analyzing tourist perceptions about the potential of tourist attraction. Demand analysis is based on the survey results to tourists and the perception of tourists about the tourist attraction that is described in social media. Based on supply and demand analysis it is concluded that the attractiveness of Teluk Kiluan is dolphin, beach sand, and diversity of fish and corals.
\end{abstract}

Keywords: tourist attraction, coastal tourism, marine tourism, supply demand approach, Kiluan Bay 


\section{PENDAHULUAN}

Pariwisata merupakan salah satu sektor andalan Indonesia. Tahun 2017 kontribusi sektor pariwisata pada Product Domestic Bruto (PDB) sebesar $5 \%$, jumlah wisatawan mancanegara mencapai 14,04 juta orang, jumlah perjalanan wisatawan manca negara mencapai 277 juta perjalanan, dan kontribusi devisa dari sektor ini mencapai 205,4 trilyun rupiah (LAKIP Kementrian Pariwisata, 2017). Kontribusi sektor pariwisata masih dapat ditingkatkan karena Indonesia memiliki potensi daya tarik yang besar, meliputi daya tarik wisata alam, budaya dan hasil buatan manusia. World Economic Forum (2015) menilai, potensi wisata alam merupakan salah satu keunggulan Indonesia. Indonesia memiliki potensi parwisata bahari sangat besar. Badan Geospacial menyatakan bahwa luas wilayah perairan Indonesia mencapai $6.315 .222 \mathrm{~km} 2$, panjang garis pantai $99.093 \mathrm{~km} 2$ dan jumlah pulau 13.466 pulau. Potensi tersebut perlu digali, sehingga dapat ditingkatkan dan dimanfaatkan untuk menarik wisatawan.

Setiap destinasi memiliki keunikkan sehingga daya tarik wisata yang ditawarkan setiap destinasi berbeda-beda, sehingga penelitian tentang daya tarik wisata masih relevan. Taman Wisata Perairan Teluk Kiluan merupakan salah satu kawasan wisata unggulan Provinsi Lampung (Rencana Induk Pengembangan Pariwisata (RIPP) Provinsi Lampung, 2011). Teluk Kiluan memiliki potensi wisata bahari, seperti pasir putih di sepanjang teluk Kiluan dan pulau Kiluan . Teluk Kiluan merupakan jalur lintasan lumba-lumba, sehingga menawarkan potensi wisata lumba-lumba. Kawasan ini juga memilik potensi keragaman hayati (Agus Dermawan, Syamsul Bahri Lubis, Suraji, 2014). Daya tarik wisata merupakan kemampuan destinasi dalam memuaskan kebutuhan pengunjung (Vengesayi, 2003). Mayo dan Jarvis (1981) dalam Vengesayi (2003) mendefinisikan daya tarik sebagai kemampuan destinasi memberikan manfaat bagi pengunjung. Daya tarik wisata merupakan kombinasi yang kompleks antara alam dan manusia. Dalam UU No 9 Tahun 2009 tentang Kepariwisataan, daya tarik wisata adalah segala sesuatu yang memiliki keunikan, keindahan, dan nilai yang berupa keanekaragaman kekayaan alam, budaya, dan hasil buatan manusia yang menjadi sasaran atau tujuan kunjungan wisatawan. Definisi daya tarik wisata pada penelitian ini adalah keunikan, keindahan dan nilai yang ditawarkan destinasi dan yang dapat memuaskan pengunjung.

Daya tarik wisata dapat diidentifikasi dengan berbagai pendekatan seperti prespektif ideografic, organizational, cognitive dan pendekatan silang yang merupakan kombinasi dari 3 pendekatan tersebut (Lew,1987). Pendekatan ideographic menekankan pada apa yg ada dilokasi dan yang bersifat nyata (tangible) sedangkan pendekatan organizational perspective menekankan pada spatial, capacity, infrastructure, temporal nature. Pendekatan cognitive menekankan pada penilaian dan pengalaman turis. Formica (2000) menimpulkan bahwa ada dua cara untuk menyimpulkan daya tarik wisata destinasi. Pendekatan supply adalah mencari hal-hal daya tarik di destinasi dan penekatan demand adalah mempelajari apa yang menarik menurut persepsi pengunjung. Formica et al menemukan bahwa tidak ada korelasi tingkat kepentingan supply dan demand. Daya tarik wisata merupakan factor pendorong dan tanpa daya tarik wisata maka tidak ada pariwisata (Ariya, Wishitemi, Sitati, 2017). Lebih lanjut dikemukakan bahwa semakin tinggi kesesuaian daya tarik destinasi dengan kebutuhan wisatawan, semakin tinggi preferensi wisatawan pada destinasi tersebut dan semakin tinggi peluang dikunjungi. Oleh karena itu penilaian daya tarik wisata 
sebaiknya ditinjau dari pendekatan supply dan pendekatan demand (Formica \& Uysal, 2006). Pendekatan demand, fokus pada pendapat, perasaan dan keyakinan wisatawan bahwa destinsi yang mereka kunjungi mampu memuaskan kebutuhan mereka. Pendekatan supply menjelaskan sumber daya pariwisata yang secara bersama-sama menimbulkan daya tarik. Supply dan demand pariwisata saling tergantung, oleh karena itu penelitian ini menggunakan pendekatan suppy dan demand.

Menurut Undang Undang nomor 10 tahun 2009 tentang kepariwisataan, daya tarik wisata didefinisikan sebagai segala sesuatu yang memiliki keunikan, keindahan, dan nilai yang berupa keragaman kekayaan alam, budaya, dan hasil buatan manusia yang menjadi sasaran atau tujuan kunjungan wisata. Daya tarik wisata digolongkan dalam daya tarik wisata alam, daya tarik wisata budaya dan daya tarik wisata hasil buatan manusia. Daya tarik wisata perlu digali, ditingkatkan kualitas dan daya tariknya serta dimantapkan untuk meningkatkan daya saing sehingga mampu menarik kunjungan ulang dan segmen pasar baru (Peraturan Pemerintah nomor 50 tahun 2011). Wisata pantai (coastal tourism) meliputi rekreasi dan pariwisata di pantai seperti berenang, berselancar, berjemur, dan wisata darat yang terkait dengan daerah pesisir, serta pasokan dan industry manufaktur yang terkait dengan kegiatan ini (Ecorys, 2013). Wisata bahari (marine tourism) meliputi pariwisata yang sebagian besar berbasis air daripada berbasis daratan misalnya berperahu, berperahu pesiar, berlayar, olahraga bahari), tetapi mencakup pengoperasian fasilitas di darat, pembuatan peralatan, dan layanan yang diperlukan untuk segmen pariwisata ini (Ecorys, 2013).

Halls (2001) menyimpulkan ada perbedaan wisata pantai (costal tourism) dan wisata bahari (marine tourism). Wisata pantai mencakup kegiatan-kegiatan yang berorientasi pada laut berjemur, berenang, snorkeling, ekowisata laut dan kegiatan pendukung aktiitas dipantai dan laut seperti retail, restoran, akomodasi dan rantai pasok pendukung kegiatan. Wisata bahari mencakup wisata pantai dan diperluas dengan aktivitas-aktivitas seperti memancing dan berlayar di laut lepas. Pada Peraturan Pemerintah nomor 50 tahun 2011 tentang Rencana Induk Pembangunan Kepariwisataan disebutkan bahwa daya tarik wisata alam diperairan laut dapat berupa bentang pesisir pantai, bentang laut dan kolam air dan dasar laut. Daya tarik bentang pesisir adalah yang ada dipantai sedangkan bentang laut meliputi pesisir pantai dan lepas pantai yang memiliki potensi bahari.

Menurut Hudisaputra (2012) Kawasan Teluk Kiluan yang luasnya 276,1km2 memiliki daya tarik darat dan laut, yang dapat dimanfaatkan untuk kegiatan pengamatan lumba-lumba, memancing, snorkeling, diving, fotografi dan edukasi ekowisata serta wisata budaya. Berdasarkan SK Bupati Tanggamus No.B.399/32/11/2014 Kawasan Wisata Teluk Kiluan merupakan kawasan konservasi perairan (KKP) daerah, KKP dimanfaatkan untuk wisata perairan seperti snorkeling, wisata pantai dan wisata lumbalumba. Potensi tersebut masih perlu digali agar dapat menjadi daya tarik wisata. Penelitian ini bertujuan untuk menggali daya tarik wisata dengan menggunakan pendekatan supply dan demand. 


\section{METODE PENELITIAN}

Metode penelitian yang digunakan pada pendekatan supply adalah studi literature. Pemilihan studi literatur dalam pendekatan supply, karena wisata bahari perlu kajian oceanografi. Literature yang dipilih adalah hasil penelitian tentang obyek yang diteliti dan metode observasi.

Berdasarkan pandapat Hadisaputra (2012) daya tarik Teluk Kiluan adalah pantai dan bahari. Ruang lingkup penelitian ini adalah wisata pantai dan wisata bahari. Lokasi observasi dilakukan dipantai teluk Kiluan dari cekungan teluk Kiluan hingga desa diseberang Pulau Kelapa dan di Pulau Kelapa. Tujuan observasi adalah untuk mengamati perilaku pengunjung dilokasi dan obyek wisata. Observasi perilaku wisatawan, lumba-lumba dan pulau Kelapa dilakukan dengan menggunakan jukung atau kapal kecil yang dari teluk Kiluan menuju lautan lepas (Samudra Indonesia) yang berjarak 7 kilometer dan pulau Kelapa. Obeservasi garis pantai Teluk Kiluan dan Pulau Kelapa dilakukan dengan menyusuri pantai berikut ini

\section{Peta Observasi}

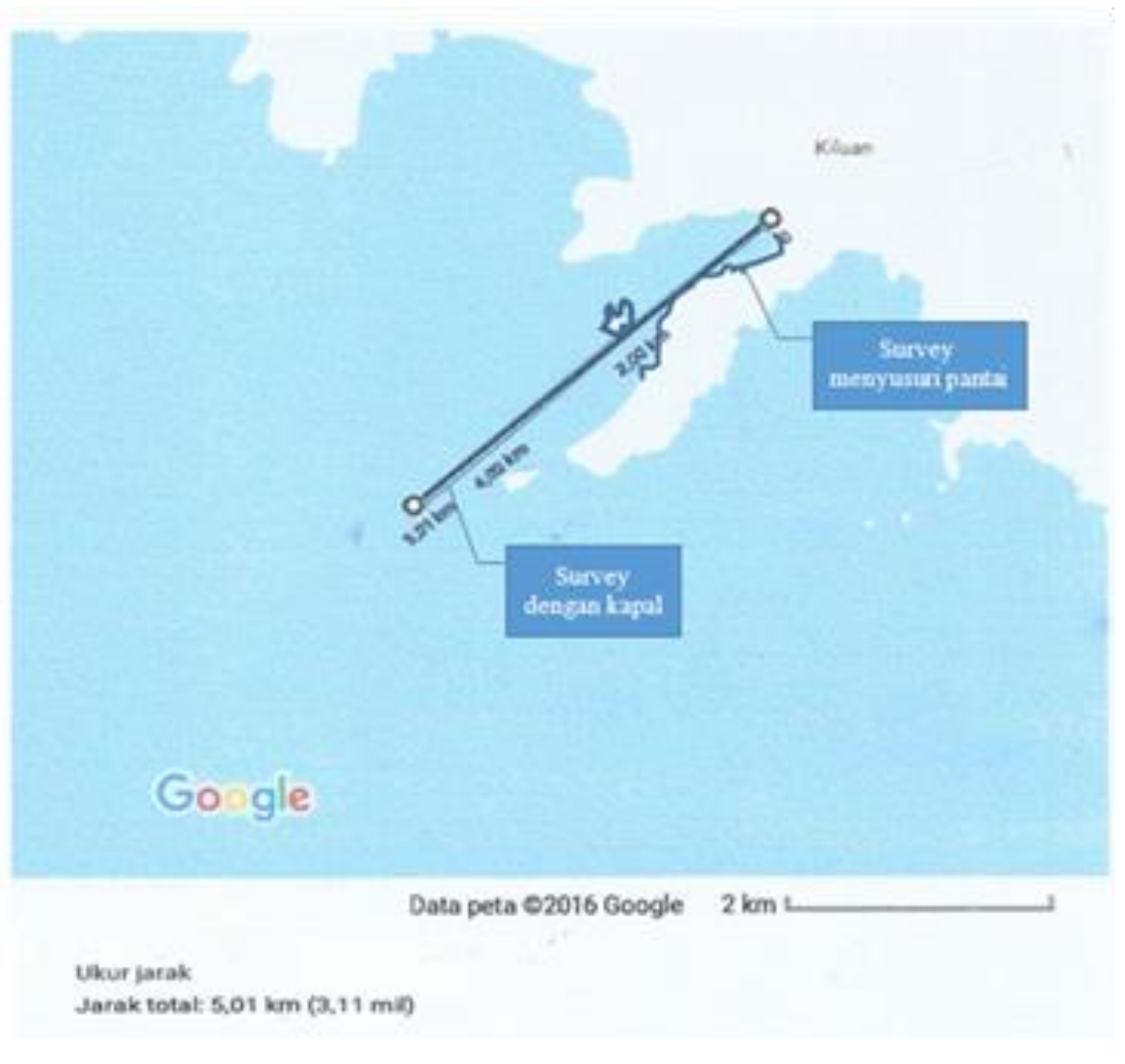


Survey dilakukan untuk mengetahui persepsi wisatawan pada daya tarik wisata yang meliputi kondisi air laut, pasir, atraksi lumba-lumba dan flora. Range persepsi adalah 1 sampai 7. 1 artinya tidak baik, sedangkan 7 artinya sangat baik. Survey dilakukan di Pantai Kiluan dan di Pulau Kelapa. Jumlah responden adalah 100 orang. Karakteristik wisatawan sebagai berikut.

Tabel 1. Karakteristik Wisatawan

\begin{tabular}{|c|c|c|}
\hline Karakteristik & Opsi & Frekuensi \\
\hline \multirow[t]{2}{*}{ Jenis kelamin } & a. Pria & 48 \\
\hline & b. Wanita & 52 \\
\hline \multirow[t]{4}{*}{ Umur } & a. $\leq 20$ tahun & 36 \\
\hline & b. $21-30$ tahun & 54 \\
\hline & c. $31-40$ tahun & 8 \\
\hline & d. $41-50$ tahun & 2 \\
\hline \multirow[t]{6}{*}{ Pendidikan terakhir } & a. Lulus SMP & 9 \\
\hline & b. Lulus SMA & 26 \\
\hline & c. Lulus D2/D3 & 12 \\
\hline & d. Lulus D4/S1 & 37 \\
\hline & e. Lulus S2 & 9 \\
\hline & f. Lulus S3 & 2 \\
\hline \multirow[t]{6}{*}{ Pekerjaan } & a. Pelajar/mahasiswa & 61 \\
\hline & b. Pegawai swasta & 18 \\
\hline & c. Pegawai negeri & 11 \\
\hline & d. Pebisnis & 6 \\
\hline & e. Profesional & 3 \\
\hline & f. Lain-lain & 1 \\
\hline \multirow[t]{5}{*}{ Frekuensi berkunjung } & a. 1 kali & 68 \\
\hline & b. 2-3 kali & 16 \\
\hline & c. 5-6 kali & 9 \\
\hline & d. 7-8 kali & 3 \\
\hline & e. 9 kali atau lebih & 4 \\
\hline \multirow[t]{5}{*}{ Sumber informasi } & a. Teman & 47 \\
\hline & b. Keluarga & 30 \\
\hline & c. Media masa & 17 \\
\hline & $\begin{array}{l}\text { d. Biro perjalanan } \\
\text { wisata }\end{array}$ & 5 \\
\hline & e. Lain-lain & 1 \\
\hline
\end{tabular}

Sumber: Data Primer Yang Diolah

Mengingat luasnya kawasan in, maka pada pendekatan demand, digunakan beberapa metode survey dengan menggunakan kuesioner dan analisis konten pada website atau blog dan youtobe yang memuat narasi dan atau video dan atau foto tentang lokasi dan aktivitas wisatawan. 
Tabel 2. Narasumber Media Sosial

\begin{tabular}{|c|c|c|}
\hline Narasumber & $\begin{array}{l}\text { Aktivitas dan } \\
\text { lokasi }\end{array}$ & Bukti \\
\hline $\begin{array}{l}\text { Jejak Langkahku Free Lance Writer } \\
\text { http://jejaklangkahku.com/2015/05/30/snorkeling- } \\
\text { sejauh-1-kilometer-di-sepanjang-teluk-kiluan- } \\
\text { lampung/ }\end{array}$ & $\begin{array}{l}\text { Snorkeling } \\
\text { disepanjang } \\
\text { teluk Kiluan }\end{array}$ & $\begin{array}{l}\text { Foto terumbu } \\
\text { karang }\end{array}$ \\
\hline $\begin{array}{l}\text { http://teguhsan- } \\
\text { journey.blogspot.co.id/2013/03/berburu-spot- } \\
\text { snorkeling-di-teluk-lampung.html }\end{array}$ & $\begin{array}{l}\text { Snorkeling di } \\
\text { halaman depan } \\
\text { homestay di } \\
\text { pulau Kelapa }\end{array}$ & $\begin{array}{l}\text { Foto terumbu } \\
\text { karang }\end{array}$ \\
\hline $\begin{array}{l}\text { http://www.wanderingdinda.com/teluk-kiluan- } \\
\text { trip/ }\end{array}$ & $\begin{array}{l}\text { Snorkeling di } \\
\text { pulau kelapa } \\
\text { depan homstay }\end{array}$ & $\begin{array}{l}\text { Foto terumbu } \\
\text { karang, foto } \\
\text { pribadi ber- } \\
\text { snorkeling }\end{array}$ \\
\hline $\begin{array}{l}\text { https://dananwahyu.com/2012/11/21/teluk-kiluan- } \\
\text { tak-hanya-lumba-lumba/ }\end{array}$ & $\begin{array}{l}\text { Snorkeling } \\
\text { Laguna }\end{array}$ & $\begin{array}{l}\text { Foto snorkeling, } \\
\text { terumbu karang, } \\
\text { laguna }\end{array}$ \\
\hline $\begin{array}{l}\text { http://yopiefranz.com/2016/03/teluk-kiluan- } \\
\text { tempat-wisata-seru-di-lampung/ }\end{array}$ & $\begin{array}{l}\text { Snorkeling di } \\
\text { teluk Kiluan. } \\
\text { Snorkeling } \\
\text { bukan aktivitas } \\
\text { utama di teluk } \\
\text { Kiluan. } \\
\text { Karang banyak } \\
\text { yang mati } \\
\text { karena diterjang } \\
\text { ombak }\end{array}$ & \\
\hline
\end{tabular}

Sumber: dari berbagai blog

Metode analisis yang digunakan adalah menganalisis kesesuaian hasil analisis pendekatan supply dan pendekatan demand. Ruang lingkup analisis adalah daya tarik untuk kegiatan bentang pantai, bentang laut dan dasar laut.

\section{HASIL PENELITIAN DAN PEMBAHASAN}

\section{Analisis Wisata Pantai}

Pasir dibeberapa lokasi di kawasan Kiluan tergolong putih dan bersih. Hasil penelitian yang dilakukan oleh Lukman Hakim,Syifa Nur Afif Giarsyah, Karizma Fahlevy (2015) menyimpulkan bahwa perairan didominasi oleh fine sand. kekeruhan tiap stasiun berbeda bergantung pada kedalaman dan densitas berkisar 1020 sampai $1021 \mathrm{~kg} / \mathrm{m}^{3}$ dengan kecerahan perairan yang masih baik dengan persentase rata-rata $91.65 \%$.

Dari hasil observasi, pasir putih dijumpai di pantai Pulau Kelapa dan di Pantai Bandung Jaya. Pasir di pantai Teluk Kiluan bercampur kerikil dan pasir pantai berwarna hitam dan difungsikan penduduk sebagai pelabuhan bagi kapal kecil (jukung) sehingga kurang bagus untuk bermain dipantai. 


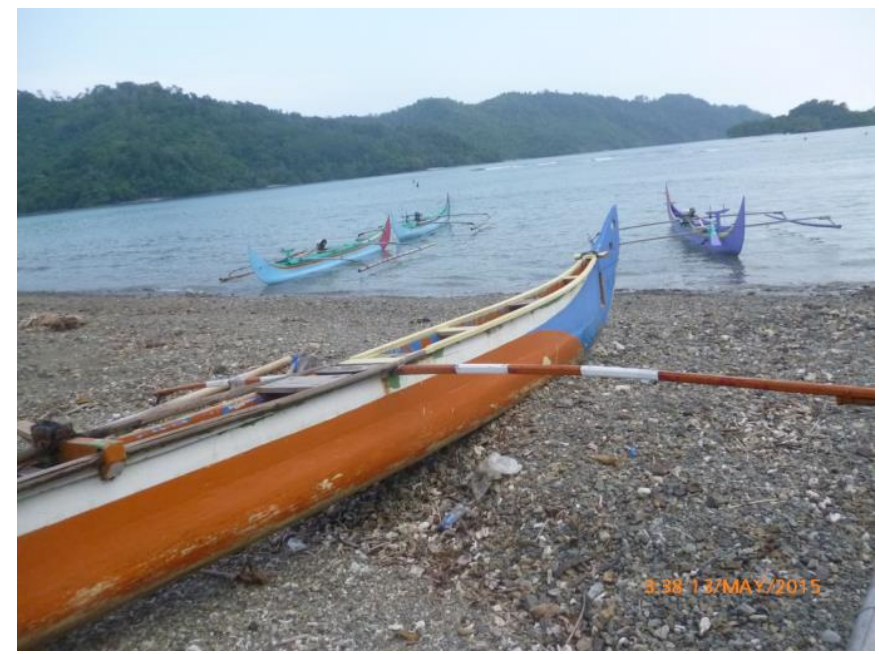

Gambar 1. Pantai Teluk Kiluan (dokumen pribadi)

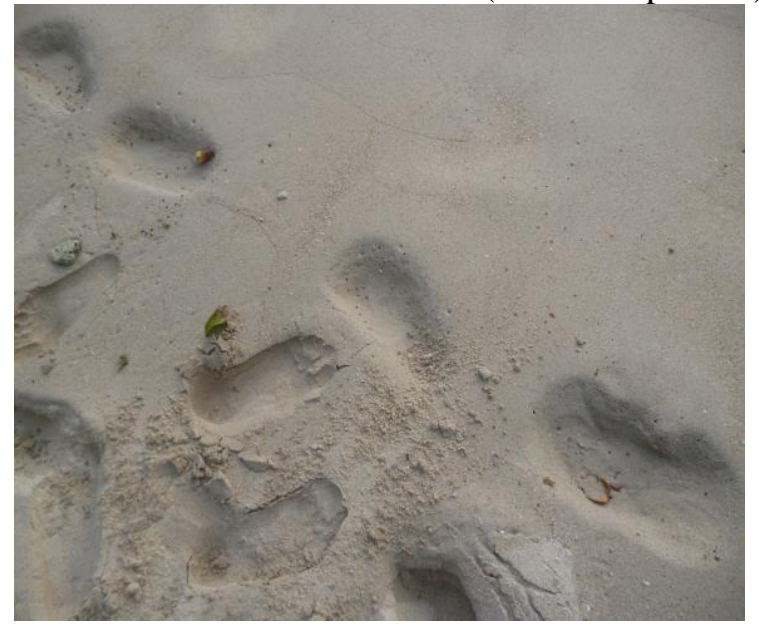

Gambar 2. Pasir Putih di Pantai Pulau Kiluan (Dokumen Pribadi)

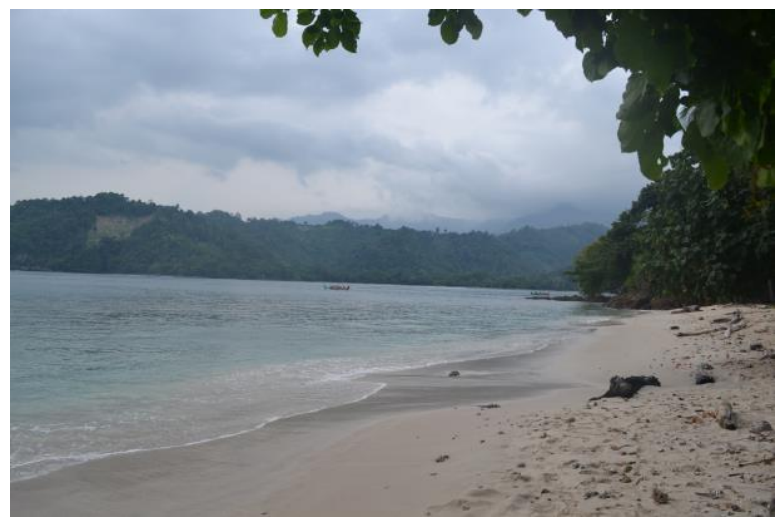

Foto 3. Pasir di pantai Bandung Jaya. Dokumen pribadi Sami Mutarom 


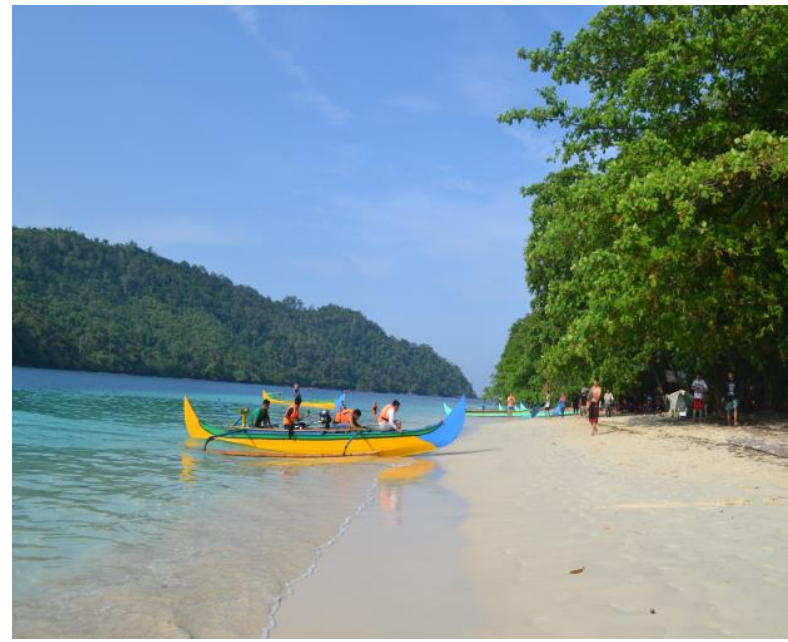

Gambar 4. Pasir di pantai Pulau Kelapa. Dokumen pribadi Sami Mutharom

Menurut responden pasir di Teluk Kiluan tergolong cukup bersih. Warna pasir di pantai juga putih. Keberadaan kerang-karang kecil mengganggu aktivitas wisatawan. Responden menilai cukup banyak di pantai.

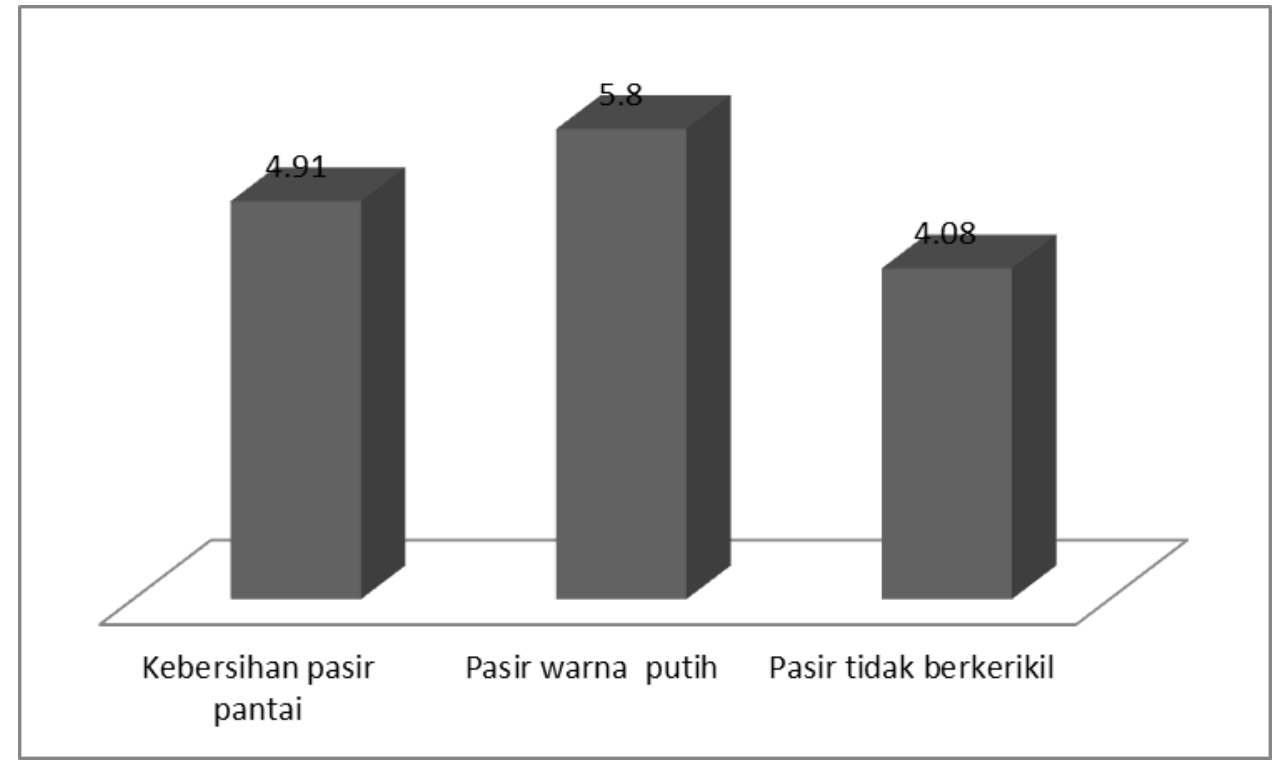

Gambar 5. Persepsi Wisatawan Tentang Pasir di Teluk Kiluan Sumber: Data Primer Yang Diolah

Topografi Teluk Kiluan sangat beragam. Wilayah ini terdiri dari daratan, persawahan dan perbukitan dengan ketinggian bervariasi mulai dari 5 sampai dengan 400 meter dibawah permukaan laut (Agus Darmawan, 2014). Kondisi ini menyebabkan Teluk Kiluan ditumbuhi beraneka ragam fauna. 


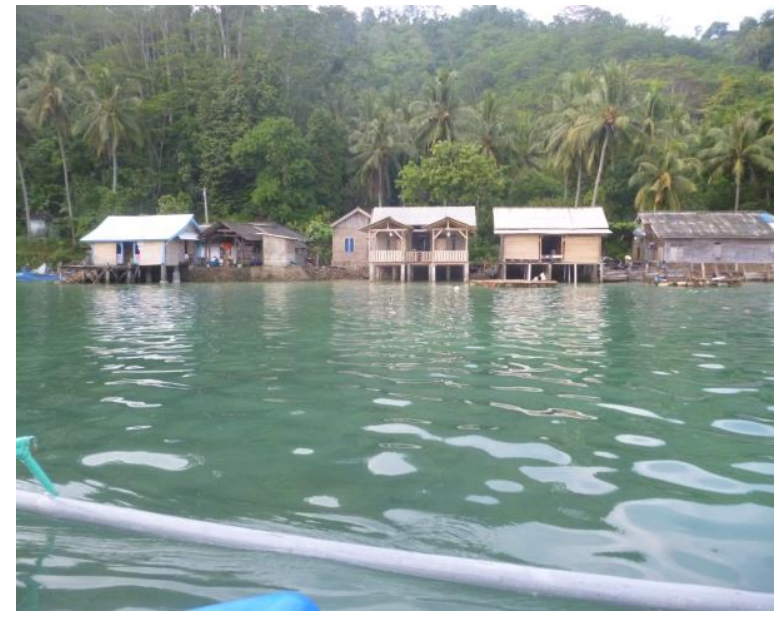

Gambar 6. Fauna di Teluk Kiluan (Dokumen Pribadi)

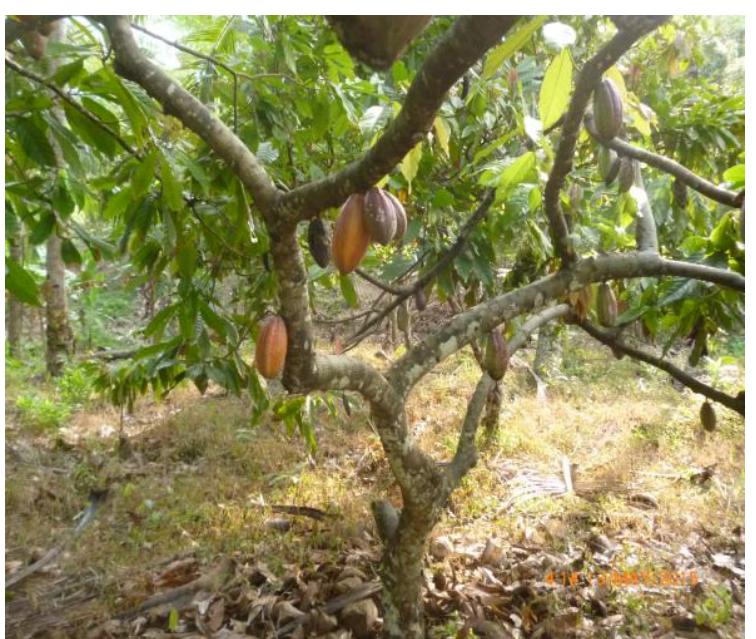

Gambar 7. Tanaman Coklat Di Sekitar Pantai Bandung Jaya. Dokumen pribadi

Berdasarkan Peraturan Daerah Kabupaten Tanggamus No. 16 Tentang Rencana Tata Ruang Wilayah Kabupaten Tanggamus Tahun 2011-2031, Kecamatan Kelumbayan ditetapkan sebagai kawasan peruntukan pertanian, holtikultura dan perkebunan. Dengan komoditas unggulan berupa sayur-sayuran, buah manggis, buah durian, kakau, kopi dan kelapa. Dari hasil observasi disepanjang pantai dijumpai pohon kelap. Pohon kakau di jumpai di jalan desa dari ekowisata Cikal menuju ke Bandung Jaya. Di Pulau Kelapa, tamanan didominasi oleh pohon waru dan kelapa. Menurut penilaian pengunjung flora di sekitar kawasan wisata Teluk Kiluan, bervariasi dan rimbun namun kurang teratur. Keragaman dan jenis flora dapat menjadi daya tarik dan perlu ditonjolkan di kawasan ini. 


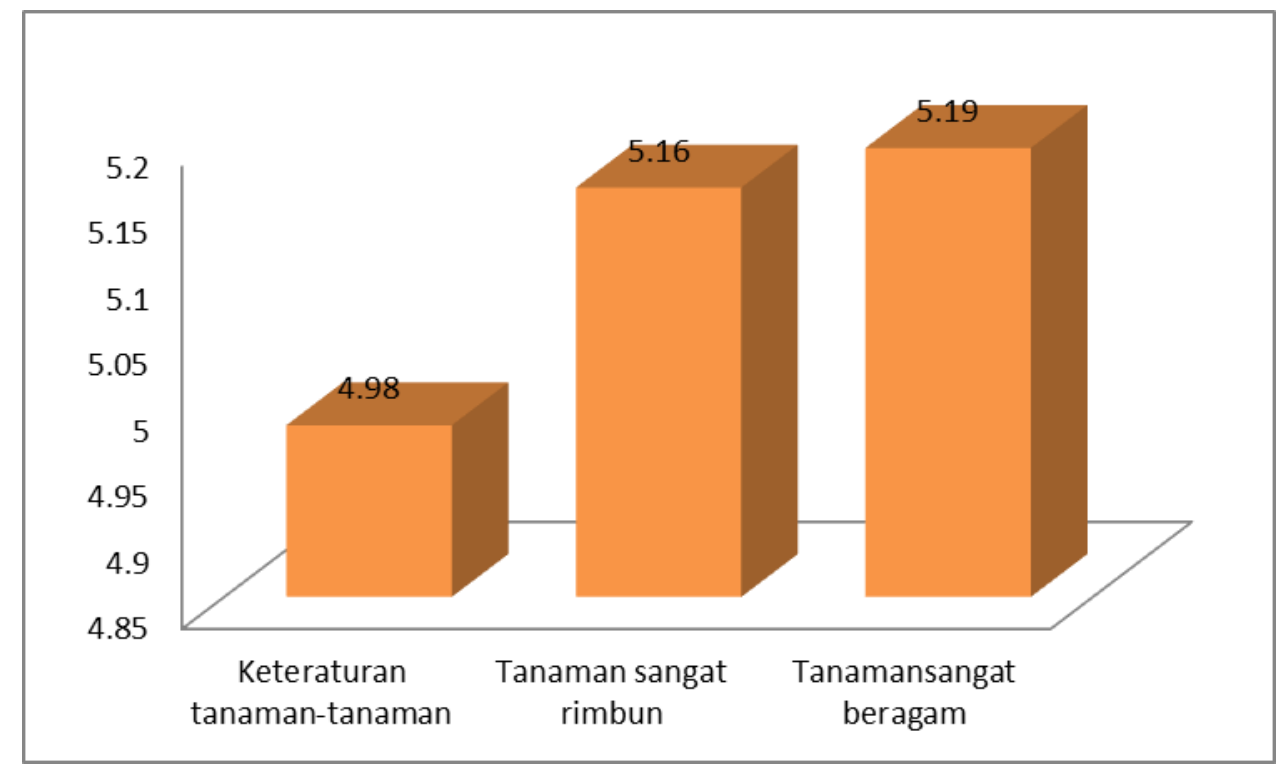

Gambar 8. Persepsi Wisatawan Tentang Flora di Teluk Kiluan

\section{Analisis Bahari}

Secara kesenilaian pengunjung tentang air laut Teluk Kiluan tergolong jenih dan bersih. Nilai rata-rata untuk kejernihan air adalah 5,79 dari rentang nilai 1 sampai 7 . Sedangkan nilai rata-rata kebersihan air adalah 5,7. Pengamatan dilapangan di 3 lokasi yaitu di Bandung Jaya dan Pantai Pulau Kiluan air laut tergolong bersih dari sampah. dan lait tergolong bersih. Hasil penelitian fisik yang dilakukan Lukman Hakim,Syifa Nur Afif Giarsyah, Karizma Fahlevy (2015) menunjukan bahwa kecerahan air Teluk Kiluan bervariasi tergantung kedalaman laut dan densitas. Secara keseluruhan kecerahan air laut di Teluk Kiluan masih baik.

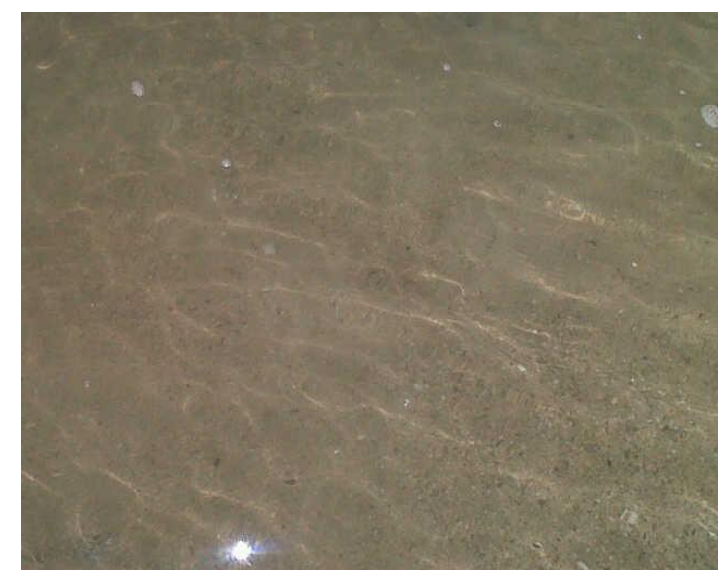

Gambar 9. Kecerahan Air Di Pantai Bandung Jaya (dokumen pribadi) 
Vol 1, No. 1, 2018

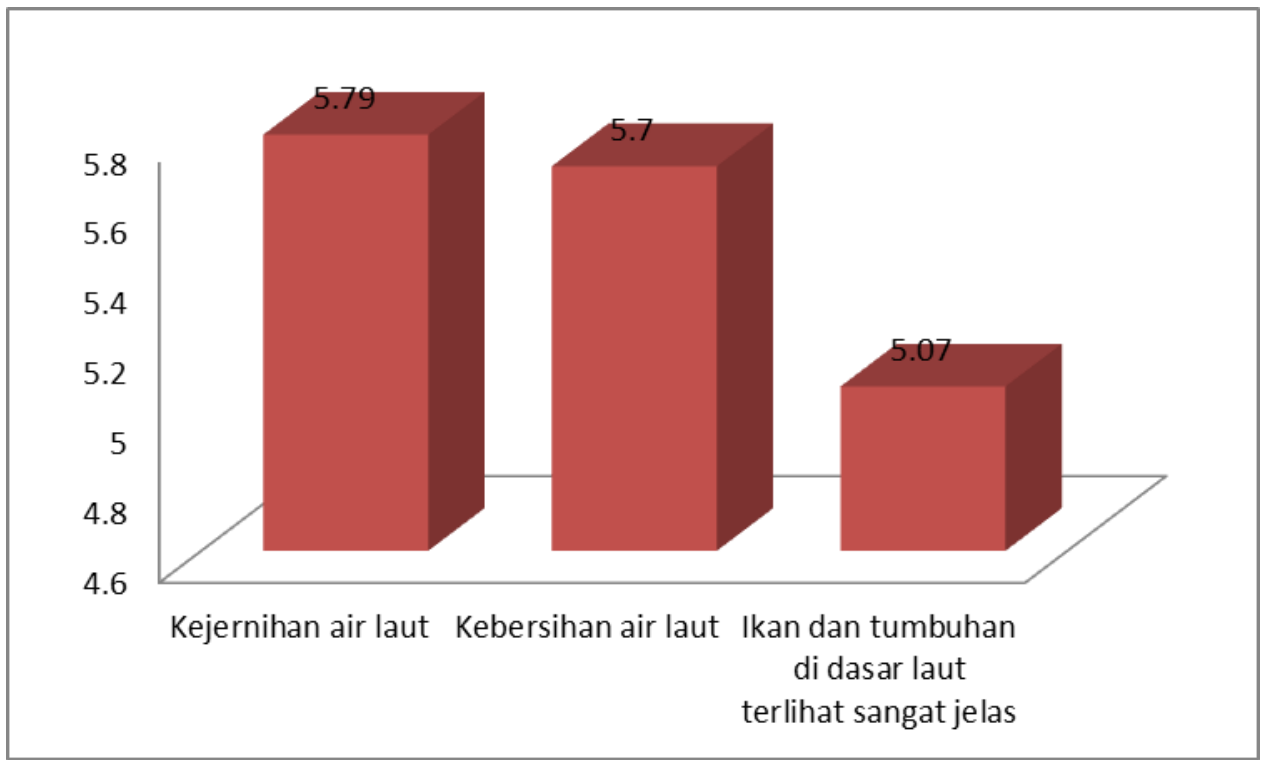

Tabel 4.Persepsi Wisatawan Tentang Kejernihan Air Laut Teluk Kiluan Sumber: Data Primer Yang Diolah

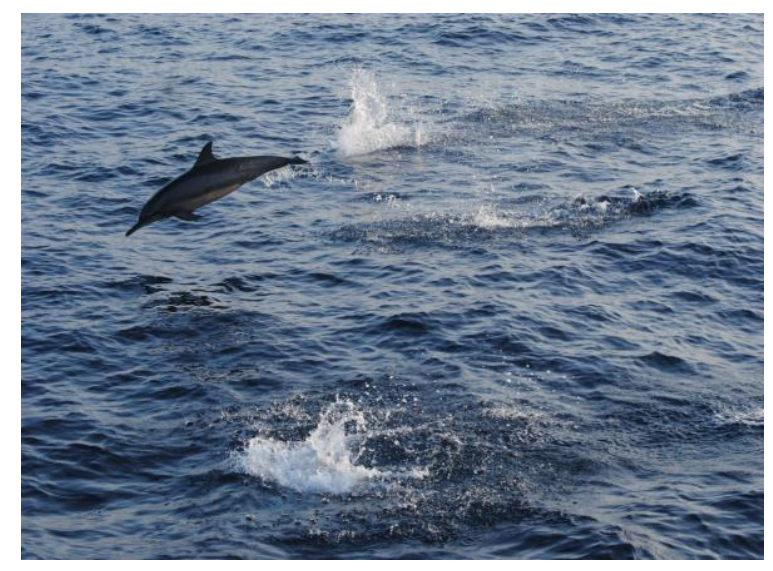

Gambar 10. Atraksi Lumba- Lumba (dokumen pribadi) 


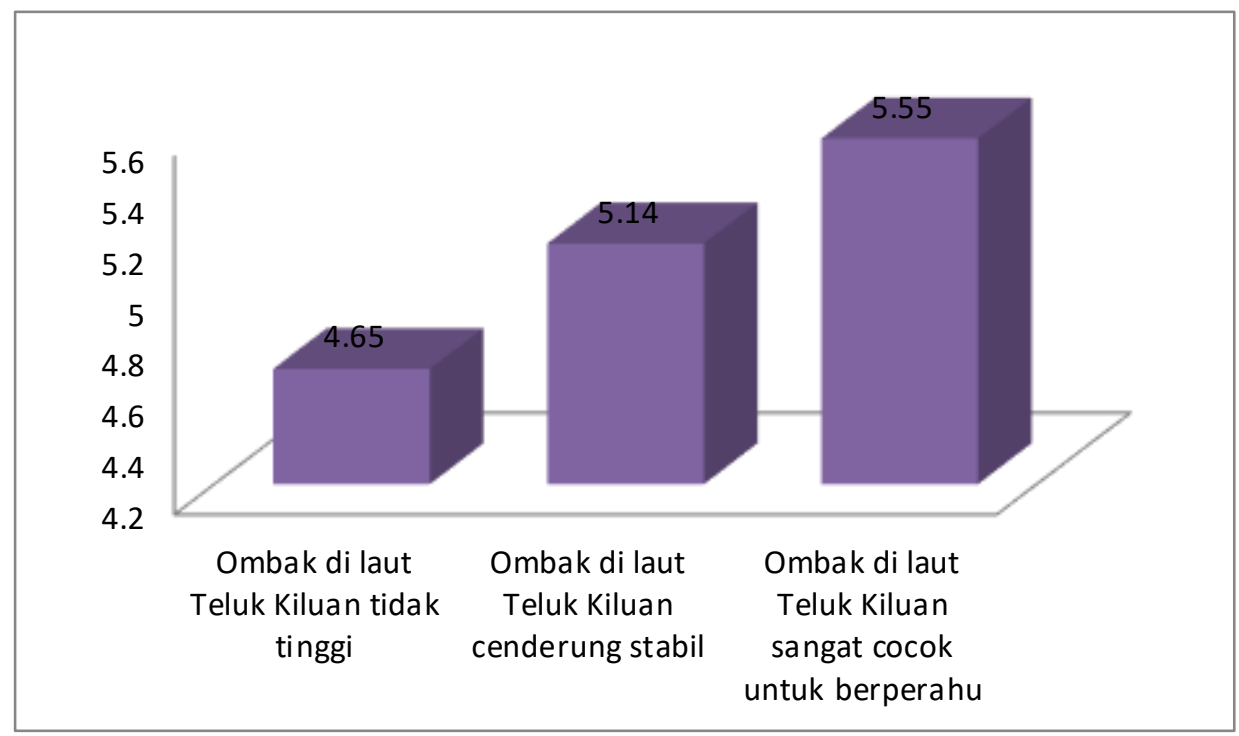

Gambar 11. Persepsi Wisatawan Tentang Ombak Teluk Kiluan Sumber: Data Primer Yang Diolah

Atraksi utama kawasan ini adalah melihat lumba-lumba di habitatnya. Menurut Tri Nur Sujatmiko dan Aulia Rahmania Putri (2015), jenis lumba-lumba yang ditemukan di teluk Kiluan adalah lumba-lumba hidung botol/bottlenose dolphin (tursiops truncatus) dan moncong panjang/ spinner dolphin (stenella longirostris). Jumlah total lumba-lumba adalah 501 ekor. Lumba-lumba ditemukan di kedalaman 150-250 meter dan berada di laut terbuka (Samudra Indonesia). Lebih lanjut dikemukakan bahwa atraksi lumba-lumba di Teluk Kiluan tergolong aman untuk dinikmati karena bottlenose dolphin termasuk hewan yang tidak menyerang. lumbalumba adalah travelling, gerakan aerials yaitu melompat ke udara, bow riding atau berenang di sebelah kapal, avoidance atau lumba-lumba yang menghindari kapal. Siahainenia (2008) menemukan bahwa pada tahun 2007 ada 2 jenis lumba-lumba di Teluk Kiluan yaitu Spinner dolphin (Stenella longirostris) yang berjumlah 541 dan Bottlenose dolphin (Tursiop truncatus) yang berjumlah 341. Atrraksi yang ditunjukan oleh lumba-lumba di Teluk Kiluan adalah melakukan travelling, aerials, feeding dan bowriding. Menurut penelaian responden daya tarik atraksi lumba-lumba dapat dilihat dengan jelas dan cukup lama serta jumlah lumba-lumba tergolong banyak.

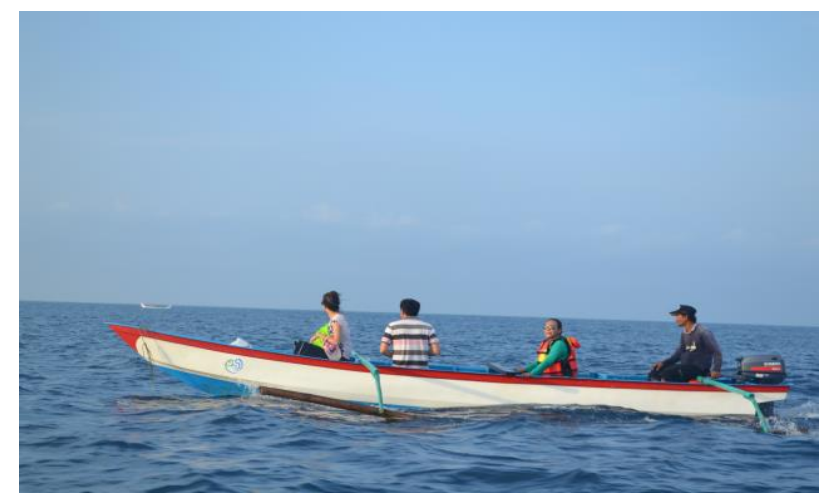

Gambar 12. Mengamati Lumba-Lumba Di Habitatnya (Dokumen Sami Mutarom) 
Atraksi lumba-lumba merupakan tujuan utama wisatawan yang datang ke teluk Kiluan. Responden menilai mereka dapat melihat atraksi lumba-lumba dengan jelas dan dalam waktu yang cukup lama dan jumlah lumba-lumba yang mereka temui cukup banyak.

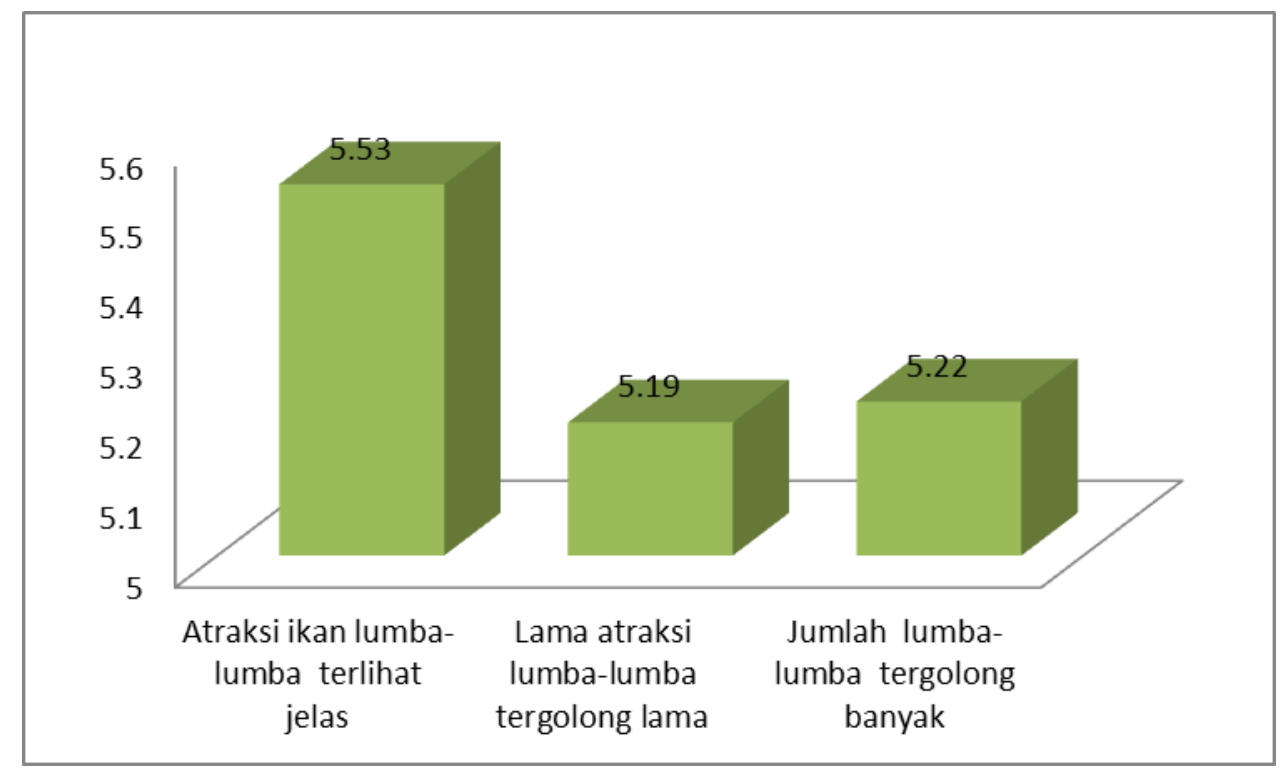

Gambar 13. Persepsi Wisatawan Tentang Atraksi Lumba-Lumba Sumber: Data Primer Yang Diolah

Teluk Kiluan berada di dalam Teluk Semangka. Menurut Pariwono (1999) ratarata kedalaman di Teluk Semangka adalah 60 meter, pada jarak $15 \mathrm{~km}$ dari kepala teluk kedalamannya mencapai $200 \mathrm{~m}$. Siahainenia et al Teluk Kiluan terlindung oleh Pulau Kelapa dan Tungtungkalik. Survey pemetaan dan pengukuran dasar laut yang dilakukan oleh Fadlil Pungkas, Nurhaya Afifah (2015) disimpulkan bahwa kedalaman Teluk Kiluan cukup variatif. Kedalaman teluk Teluk Kiluan bagian dalam berkisar 0-20 meter sedangkan bagian luar teluk berkisar 20-40 meter. Kedalaman di luar Teluk Kiluan >40 meter. Kedalaman di bagian utara Pulau Kelapa adalah 0-18 meter dan dibagian Selatan 0-39 meter.

Kedalaman laut yang beragam mempengaruhi aktivitas wisatawan di Kawasan Teluk Kiluan. Dari obeservasi disimpulkan bahwa pungunjung melakukan aktivitas di dalam laut seperti snorkeling dan di atas laut seperti berperahu, berenang atau bermain ombak didekat bibir dipantai terutama di sebelah utara Pulau Kelapa dan di Pantai Bandung Jaya. Pengunjung menilai bahwa Kawasan wisata Teluk Kiluan memiliki daya tarik yang tinggi untuk snorkeling dan berenang atau bermain air di pinggir pantai. Berdasarakan pengalaman pengunjung yang diunggah dalam website dan youtube bahwa ada 3 spot snorkeling di kawasan ini pertama di Pulau Kelapa dan 2 spot di Pantai Teluk Kiluan (http://jejaklangkahku.com/2015/05/30/snorkeling-sejauh-1kilometer-di-sepanjang-teluk-kiluan-lampung/). Teluk Kiluan walaupun tergolong landai tetapi tidak cocok untuk berenang dan bermain pinggir pantai, karena pantainya berlumpur.

Snorkeling terkait dengan terumbu karang dan ikan. Aflaha Abdul Munib, Amri (2015).Terumbu karang berperan dalam mempertahakan biota laut. Sabrian, Triana, Yuda Alam Perdana (2015) menyimpulkan bahwa terumbu karang didominasi oleh karang keras (hard coral). Kondisi karang yang diukur dengan Indeks Mortalitas Karang 
(IMK) menunjukkan bahwa kondisi karang keras dibagian selatan Teluk Kiluan tergolong dalam kategori buruk sedangkan karang dibagian barat Nilai pulau Kiluan/Kelapa tergolong sangat baik sedangkan di bagian Selatan Teluk Kiluan tergolong sangat buruk (Agus Darmawan, Syamsul Bahri Lubis, Surak, 2014). Penelitian ini menguatakan pendapat responden bahwa laut di sebelah utara Pulau Kiluan menarik untuk snorkling karena terumbu karangnya dala kondisi yang baik. Berdasarkan pengalaman yang dituangkan dalam http://jejaklangkahku.com/2015/05/30/snorkeling-sejauh-1-kilometer-di-sepanjang teluk-kiluan-lampung diteluk Kiliuan terdapat 3 lokasi snorkeling yaitu 2 lokasi disepanjang Teluk Kiluan dan 1 lokasi sekitar di pulau Kelapa. Pengalaman snorkeling di pulau kelapa diunggah di https://www.youtube.com/watch? $\mathrm{v}=\mathrm{SaIdSrI7rOk}$ yang dipublikasi 26 November 2014 dan https://www.youtube.com/watch?v=T3PVnOejYFw dipublikasikan 26 Januari 2016 dan https://www.tripadvisor.co.id/ShowUserReviewsg3380109-d3295839-r251378440-Teluk_Kiluan-Tanggamus_Lampung_Sumatra.html

Menurut pengalaman pengunjung snorkling bukan daya tarik utama. Pendapat ini didukung hasil Ekspedisi Himiteka 2015 menemukan 18 Famili dengan 66 spesies ikan karang. (Ariefianto Tri Mahadi, Thomas A. P. Simarmata, Yuda Alam Perdana, 2015). Temuan lainnya adalah diperairan Teluk Kiluan memiliki keanekaragaman ikan yang rendah, keseragaman ikan juga rendah dan dominasi ikan juga rendah, hal ini disebabkan oleh kondisi komunitas terumbu karang. Jenis - jenis bentuk pertumbuhan yang ditemukan mencapai 9 bentuk pertumbuhan dan didominasi oleh life form acropora bercabang (ACB), selain itu tutupan karang didominasi oleh genus Acropora. Foto diri pengunjung yang diunggah di http://www.wanderingdinda.com/teluk-kiluan-trip/ dan http://faisalrais20.blogspot.co.id/2014/11/paket-dive-dan-snorkeling-specialtahun.html serta http://eisforebby.blogspot.co.id/2012/08/kiluan-trip.html mengungkapkan kondisi terumbu karang dan ikan dilokasi snorkling. Lukman Hakim, Syifa Nur Afif Giarsyah, Karizma Fahlevy (2015) mengukur beberapa parameter fisik oceanografi di Teluk Kiluan. Suhu di Teluk Kiluan antara $28^{\circ} \mathrm{C}$ sampai $30^{\circ} \mathrm{C}$, salinitas (kadar garam) antara 32.50 sampai dengan 33.60, dengan ketinggian mean sea level (rata-rata kenaikan permukaan laut adalah $200 \mathrm{~cm}$, arah arus beragam bergantung pada angin permukaan, sedimen dasar perairan didominasi oleh fine sand, kekeruhan disetiap lokasi berbeda-beda tergantung pada kedalaman dan densitas berkisar 1020 sampai $1021 \mathrm{~kg} / \mathrm{m}^{3}$ dengan kecerahan perairan yang masih baik dengan persentase rata-rata 91.65\%. Ekspedisi Himiteka 2015 menemukan 18 Famili dengan 66 spesies ikan karang. (Ariefianto Tri Mahadi, Thomas A. P. Simarmata, Yuda Alam Perdana, 2015). Temuan lainnya adalah diperairan Teluk Kiluan memiliki keanekaragaman ikan yang rendah, keseragaman ikan juga rendah dan dominasi ikan juga rendah, hal ini disebabkan oleh kondisi komunitas terumbu karang. Jenis - jenis bentuk pertumbuhan yang ditemukan mencapai 9 bentuk pertumbuhan dan didominasi oleh life form acropora bercabang (ACB), selain itu tutupan karang didominasi oleh genus Acropora.

Hasil analisis pendekatan supply dan demand dirangkum sebagai berikut. Atraksi lumba-lumba yang ditawarkan oleh alam Teluk Kiluan direspon dengan baik oleh wisatawan.Dengan demikian supply cocok dengan demand. Kualitas pasir yang ditawarkan oleh Teluk Kiluan, direspon dengan baik oleh wisatawan. Supply cocok dengan demand. Kondisi air yang bersih serta didukung oleh keindahan terumbu karang dan keragaman ikan, sesuai dengan demand wisatawan yang melakukan aktivitas snorkeling. 
Tabel 6. Rangkuman Analisis Supply Demand dan Daya Tarik Wisata

\begin{tabular}{|c|c|c|}
\hline Pendekatan supply & pendekatan demand & Daya tarik Wisata \\
\hline $\begin{array}{l}\text { 1. Jenis lumba-lumba } \\
\text { 2. Jumlah lumba- } \\
\text { lumba } \\
\text { 3. Atraksi lumba- } \\
\text { lumba }\end{array}$ & $\begin{array}{l}\text { 1. Jumlah lumba- } \\
\text { lumba yang diamati } \\
\text { wisatawan } \\
\text { 2. Atraksi lumba- } \\
\text { lumba dapat diamati } \\
\text { dengan jelas } \\
\text { 3. Atraksi lumba- } \\
\text { lumba dapat dilihat } \\
\text { dalam waktu yang } \\
\text { cukup lama }\end{array}$ & $\begin{array}{lll}\text { Lumba-lumba } & \text { yang hidup } \\
\text { dihabitatnya } & \text { di } & \text { Teluk } \\
\text { Kiluan } & & \end{array}$ \\
\hline $\begin{array}{l}\text { 1. Kualitas pasir di } \\
\text { pantai } \\
\text { 2. Ombak di pantai }\end{array}$ & $\begin{array}{l}\text { 1. Pasir dipantai } \\
\text { sangat bersih } \\
\text { 2. Pasir dipantai } \\
\text { sangat putih } \\
\text { 3. Pasir dipanti tidak } \\
\text { berkerikil }\end{array}$ & $\begin{array}{l}\text { Pasir putih di pantai Teluk } \\
\text { Kiluan }\end{array}$ \\
\hline $\begin{array}{ll}\text { 1. } & \text { Terumbu karang } \\
\text { 2. } & \text { Ikan karang } \\
\text { 3. } & \text { Kualitas air } \\
\text { 4. } & \text { Kedalaman laut }\end{array}$ & $\begin{array}{l}\text { 1. Air sangat jernih } \\
\text { 2. Air sangat bersih } \\
\text { 3. Kualitas karang } \\
\text { (blog/youtube) } \\
\text { 4. Ikan karang } \\
\text { (blog/youtobe) }\end{array}$ & $\begin{array}{l}\text { Ikan dan karang yang dapat } \\
\text { diamati di dalam laut Teluk } \\
\text { Kiluan }\end{array}$ \\
\hline
\end{tabular}

\section{KESIMPULAN DAN SARAN}

Teluk Kiluan menawarkan daya tarik di pantai dan lepas pantai, dan daya tarik tersebut direspon baik oleh wisatawan. Untuk menjaga daya tarik wisata, wisatawan perlu diingkatkan untuk tidak merusak terumbu karang. Selain itu wisatawan perlu diingatkan tentang tinggi ombak.

Penelitian ini belum membahas daya tarik hutan bakau dan laguna. Dengan menggunakan pendekatan supply demand disarankan disarankan agar meneliti daya tarik tersebut sehigga diperoleh gambaran yang lengkap.

\section{UCAPAN TERIMA KASIH}

Ucapan terima kasih disampaikan kepada Bapak Sami Muhtarom dari Dinas Parwisata Dan Ekonomi Kreatif Provinsi Lampung. 


\section{DAFTAR PUSTAKA}

Ariya, G.,Wishitemi, B., Noah Sitati, N. (2017). Tourism Destination Attractiveness as Perceived by Tourists Visiting Lake Nakuru National Park, Kenya International Journal of Research in Tourism and Hospitality, 3(4) : 1-13

Formica, S., \& Uysal, M. (2006). Destination attractiveness based on supply and demand evaluations: An analytical framework. Journal of Travel Research, 44(4), 418-430.

Hall, C. M. (2001). Trends in ocean and coastal tourism: the end of the last frontier?. Ocean \& coastal management, 44(9-10), pp. 601-618.

Lew, A.A., 1987. A Framework of Tourist Attraction Research.Annals of Tourism Research. Vol 14, pp 553-575.

\section{Buku}

Agus Dermawan, Syamsul Bahri Lubis, Suraji. (2014). Status Pengelolaan Efektif Kawasan Konservasi Perairan, Pesisir dan Pulau-Pulau Kecil di Indonesia.

Direktorat Konservasi Kawasan dan Jenis Ikan Direktorat Jenderal Kelautan, Pesisir dan Pulau-pulau Kecil Kementrian Kelautan dan Perikanan Republik Indonesia.https://surajis.files.wordpress.com/2016/03/profil-kawasan-konservasiperairan-pesisir-dan-pulau-pulau-kecil-se-sumatera.pdf. [Diakses pada tanggal 15 September 2015].

Pariwono, J.I. (1999). Kondisi Oceanografi Perairan Pesisir Lampung. www.crc.uri.edu/download/oseanografi.pdf [Diakses pada tanggal 15 September 2015].

\section{Artikel dari konferensi ilmiah/prosiding}

Vengesayi, S. (2003, December). Destination Attractiveness and Destination Competitiveness: A Model of Destination evaluation. In ANZMAC 2003 Conference Proceedings Adelaide (pp. 1-3).

\section{Disertasi/tesis/skripsi}

Formica.S., (2000). Destination Attractiveness As Fuction of Supply and Demand Interaction. Desertation, Faculty of the Virginia Polytechnic Institute and State University.

Hudisaputra, A.K (2012). Pengelolaan Wilayah Pesisir Teluk Kiluan, Kabupaten Tanggamus Melalui Pengembangan Ekowisata. Tesis Program Studi Magister Ilmu Lingkungan Program Pascasarjana Universitas Padjadjaran Universitas Padjadjaran http://www.academia.edu/9166124/EKOWISATA_TELUK_KILUAN [diakses pada tanggal 4 September 2016]. 
Siahainenia, S.R (2008). Kajian Tingkah Laku, Distribusi Dan Karakter Suara LumbaLumba Di Perairan Pantai Lovina Dan Teluk Kiluan Lampung. Tesis Sekolah Pascasarjana Institute Pertanian Bogor. https://core.ac.uk/download/pdf/32346076.pdf [diakses pada tanggal 14 September 2016]

\section{Website / laman}

Aflaha Abdul Munib, Amri Sabrian, Triana, Yuda Alam Perdana, Kondisi Komunitas Dasar Perairan Terumbu Karang Teluk Kiluan dan Sekitarnya. Tersedia di http://himiteka.lk.ipb.ac.id/2015/12/29/kondisi-komunitas-dasar-perairanterumbu-karang-teluk-kiluan-dan-sekitarnya/ [Diakses tanggal 29 Desember 2015].

Ariefianto Tri Mahadi, Thomas A. P. Simarmata, Yuda Alam Perdana, STRUKTUR KOMUNITAS IKAN KARANG DI PERAIRAN TELUK KILUAN. Tersedia di http://himiteka.lk.ipb.ac.id/2015/12/31/struktur-komunitas-ikan-karang-diperairan-teluk-kiluan/ [Diakses tanggal 29 Desember 2015].

Badan Informasi Geospasial, tersedia di http://www.big.go.id/berita-surta/show/bigbersama-kkp-dan-kemdagri-target-pembakuan-4000-nama-pulau-pulau-diindonesia [Diakses tanggal 7/20/2018 pukul $3.01 \mathrm{pm}$ ].

Fadlil Pungkas1, Nurhaya Afifah, Batimetri Perairan Teluk Kiluan. Tersedia di http://himiteka.lk.ipb.ac.id/2015/12/29/batimetri-perairan-teluk-kiluan/ [Diakses tanggal 29 Desember 2015].

LAKIP Kemenpar 2017, Tersedia di http://www.kemenpar.go.id/userfiles/LAKIP\%202017\%20250518.pdf [Diakses tanggal 20/7/2018 pukul $02.54 \mathrm{pm}$ ].

Lukman Hakim1,Syifa Nur Afif Giarsyah1, Karizma Fahlevy, Pengukuran Parameter Fisik Oseanografi di Teluk Kiluan, Lampung. Tersedia di http://himiteka.lk.ipb.ac.id/2015/12/31/pengukuran-parameter-fisik-oseanografidi-teluk-kiluan-lampung/ [Diakses tanggal 31 Desember 2015].

Jejak Langkahku Free Lance Writer (Diakses dari http://jejaklangkahku.com/2015/05/30/snorkeling-sejauh-1-kilometer-disepanjang-teluk-kiluan-lampung/).

PERATURAN DAERAH PROVINSI LAMPUNG NOMOR 6 TAHUN 2012 RENCANA INDUK PEMBANGUNAN PARIWISATA DAERAH (RIPPDA)PROVINSI LAMPUNG [Diakses dari https://anzdoc.com/queue/peraturan-daerah-provinsi-lampung-nomor-6-tahun2012-tentang.html tanggal 24/7/2018]. 
The Travel \& Tourism Competitiveness Report. (2017). Tersedia di http://ev.am/sites/default/files/WEF_TTCR_2017.pdf [Diakses tanggal 20/7/2018 pukul $02.51 \mathrm{pm}]$

Tri Nur Sujatmiko, Aulia Rahmania Putri, JENIS DAN DISTRIBUSI LUMBALUMBA DI PERAIRAN TELUK KILUAN LAMPUNG, Tersedia di http://himiteka.lk.ipb.ac.id/2015/12/31/jenis-dan-distribusi-lumba-lumba-diperairan-teluk-kiluan-lampung/ [Diakses tanggal 31 Desember 2015] 